INDEPENDENT JOURNAL OF MANAGEMENT \& PRODUCTION (IJM\&P)

http://www.ijmp.jor.br V. 11, n. 5, Special Edition IFLOG 2019 -September 2020 ISSN: 2236-269X

DOI: 10.14807/ijmp.v11i5.1284

\title{
EFFICIENT SETUP OF THE BELT CONVEYOR SPEED THROUGH OF TEMPLATES
}

\author{
Daniel Corrêa da Silva \\ IFRJ, Brazil \\ E-mail: danielsilvanilo@gmail.com \\ Carlos Eduardo Soares Maia \\ IFRJ, Brazil \\ E-mail: carloseduardosoares2001@gmail.com \\ Letícia Ali Figueiredo Ferreira \\ CEFET/RJ, Brazil \\ E-mail: leticialifig@gmail.com \\ Ana Carla de Souza Gomes dos Santos \\ IFRJ and CEFET/RJ, Brazil \\ E-mail: ana.carla@ifrj.edu.br \\ Genildo Nonato Santos \\ IFRJ, Brazil \\ E-mail: genildo.santos@ifrj.edu.br
}

Submission: $2 / 25 / 2020$

Revision: $3 / 3 / 2020$

Accept: 3/6/2020

\section{ABSTRACT}

It is not obvious to adjust the speed of a conveyor belt so that it is possible to optimize the transport for each piece conveyed even with various studies presented in this area. The complex methodologies that are shown and the many adaptations indicated in these studies may contribute to the low adoption of these configurations. A study made, in this work, from videos of advertisements showing belt conveyor in operating on the factory floor which presented only $44 \%$ efficiency. In this work, it was shown, through theoretical studies, a mathematical model that presents the relationship between the speed and the transport capacity of conveyor belts. Based on a model, a graphical method (using templates) has been proposed that helps in choosing the conveyor belt speed for most efficient configurations that can be identified and adopted simply and without many adaptations to the system as a whole. 
DOI: 10.14807/ijmp.v11i5.1284

Keywords: belt conveyor speed; belt conveyor load; belt conveyor energy consumption; graph method for efficient solutions

\section{INTRODUCTION}

The conveyor belt is the most versatile and widespread to move the production inside industries (DIAS; LIMA; TOSTES, 2008) because it is very trustable and it stands out by its higher level of productivity and lowers the cost of maintenance (NOGUEIRA, 2004). The efficiency of a production line would be compromised if a perfect functioning of the processes of transportation of raw material, semi-finished and finished products was not ensured, in all stages of its manufacture, from the beginning to the finished product (NOGUEIRA, 2004). Due to the mentioned characteristics, the conveyor belt is a fundamental equipment inside an industry. In that way, the study and the implementation of management techniques that aim for the energetic efficiency of these devices are highly relevant in the industry sector (DIAS; RAMALHO, 2009).

Efficiency studies applied to conveyor belt are often found in the technical literature. Tsai and Lee (1996) presented a belt position control using a robust controller in a fixed operation point. In Dias, Lima, and Tostes (2008), a strategy type LQG-LTR is used to control the conveyor belt speed where a neural-net estimates the most efficient speed of the conveyor device. In Shiton (2010), is discussed a mathematical model that optimizes the electric power consumed in a conveyor belt.

However, all those methods, that depend on complicated adaptations of the controlling equipment, are rarely implemented on the nation's industries factory floors.

This work presents a study made on the efficiency related to the speed of conveyor belts, based on in national advertisements videos, published by companies that sell this type of equipment. The result of this study can be used as an indication that optimal methods of adjusting the speed of the belts are not usually adopted in Brazilian industries. As a major contribution of this work, it is suggested an efficient method of adjusting the belt speed, based on simple templates, that do not require any adaptation about the installation of new equipment to be adopted on the factory floor.

To that end, the paper presents the main theoretical foundations in chapter 2 , the work methodology in chapter 3, the results and discussions in chapter 4 , and, finally, the final considerations in chapter 5 . 
DOI: 10.14807/ijmp.v11i5.1284

\section{THEORETICAL FOUNDATION}

To allow a superficial survey of the relationship between the efficiency and speed of conveyor belts in the national industrial park, a study of advertising videos published by suppliers of this type of equipment in the country was done. Many videos with advertisements for conveyor belts, in operation, installed in industries can be found on the internet. When analyzing several of these videos, it was noticed that the belts were operating much below their maximum transport capacity - the ratio between the visible area of the belt being used to transport products and the total area of the conveyor belt (ŠTATKIĆ et al., 2015).

That is, based on the assumption that on the conveyor belt, in the space between two products being transported in sequence, there is no room for anything else, it can be considered that this conveyor is operating at its maximum transport capacity. The transport capacity of a conveyor belt is a function of several parameters, including the conveyor belt speed (ŠTATKIĆ et al., 2015). For this conclusion, imagine a tram that always runs at a constant speed and possible passengers that depart from random points to meet the tram.

If the speed with which passengers move to board the tram is considered equal, the faster the tram travels, the fewer passengers can board. Similarly, a very fast belt conveyor tends to have less area occupied by-products transported than a slower belt conveyor. However, it is not so obvious to answer whether the fastest moving tram, at the end of the same period, carries more or fewer passengers than the slowest tram.

Just as it is not obvious to say at what speed the belt conveyor, at the end of the same time, will transport more products. As there is a direct relationship between reducing speed and reducing electricity consumption on moving belts (SHIRON, 2010), the question to be asked at this point is whether it is possible to reduce the speed of the treadmill, keeping the same amount of products transported in the same period, thus reducing energy consumption.

For the answer to this question, it is necessary to understand how the speed of the conveyor is related to the capacity to transport products of the belt conveyor. Thus, this relationship will be deduced from the information obtained in generic works that talk about the modeling of transport or that talk about efficiency measures in conveyor belts (HILTERMANN et al., 2011). 
DOI: 10.14807/ijmp.v11i5.1284

\subsection{Relation between the speed and the transport capacity}

In different models, the terms usual speed $\left(v_{0}\right)$ and usual capacity $\left({ }^{C_{0}}\right)$ are the speed and the transport capacity that is initially adjusted for the operation of the treadmill. However, it is not possible to adjust these two parameters separately. The reduction in speed of the conveyor will cause a change in the transport capacity, as well as the example of the tram that was given previously, as long as the properties of the lines that feed the conveyor do not change. That is, the number of products per unit of the time they reach the treadmill does not change.

The terms $v_{r}$ and $c_{r}$ are the percentages of belt speed reduction and the change in transport capacity. Thus, reducing the speed by a percentage of $v_{r}$ will cause a change in the effective transport capacity in $c_{r}$. The best assumption to make is that the relationship between $v_{r}$ and $c_{r}$ is non-linear, $c_{r}=f\left(v_{r}\right)$. However, for small speed reductions, this non-linear relationship can be approximated to a linear relationship using the Taylor series (CHAPRA; CANALE, 2016), Equation (1), truncated in its second term. Taylor's series is a mathematical tool that allows expanding any function in a polynomial series of infinite terms whose coefficients are calculated from operations of derivatives of degree (i).

$$
\begin{aligned}
& f\left(v_{r}\right)=\sum_{i=0}^{1}\left(v_{r}-v_{r 0}\right)^{i} \cdot \frac{f^{(i)}\left(v_{r 0}\right)}{i !}+R_{2}\left(v_{r}\right) \\
& R_{2}\left(v_{r}\right)=\left(v_{r}-v_{r 0}\right)^{2} \cdot \frac{f^{(2)}\left(v_{r 0}\right)}{2 !}
\end{aligned}
$$

The operations of derivatives of degree $\mathrm{i}$ is a function related to $v_{r}$, and, $R_{2}\left(v_{r}\right)$ is the approximation error when the series is truncated in its second term.

The literature recommends that approximations are made to the surroundings of the initial point of operation of the model because the errors related to this approximation are directly proportional to that distance. And in this case, $v_{r 0}$ is the starting point. The term $f^{(1)}\left(v_{r 0}\right)$ that appear when expanding the Equation (1), $c_{r} \approx f\left(v_{r 0}\right)+f^{(1)}\left(v_{r 0}\right) \cdot\left(v_{r}-v_{r 0}\right)$, is interpreted as being an inclination factor of a linear function that was calculated as a result of the Taylor expansion. Equation (2) is the result of the substitution of the term $f^{(1)}\left(v_{r 0}\right)$ in Equation (1) by the term $k_{b}$, commonly used in the literature. In the deduction of Equation (2), 
it is common to consider that $f\left(v_{r 0}\right)$ is equal to zero when $v_{r 0}$ is equal to zero. That is, at this point, there is no change in parameters $v_{0}$ and $c_{0}$ the belt works as it was initially adjusted. $c_{r} \approx v_{r} \cdot k_{b}$

The approximation sign that appears in Equation (2) is because the truncation error $R_{2}\left(v_{r}\right)$ was removed from the original expression, Equation (1). In Taylor's series, the truncation error $R_{n}\left(v_{r}\right)$ is always greater than or equal to the term $R_{n+1}\left(v_{r}\right)$. Thus, it is expected that $R_{1}\left(v_{r}\right) \geq R_{2}\left(v_{r}\right)$, a factor that helps in the development of the expression $\left(v_{r}-v_{r 0}\right)^{1} \cdot k_{b} \geq R_{2}\left(v_{r}\right)$. Thus, the truncation error $R_{2}\left(v_{r}\right)$ always remains less than or equal to the value that is the result of the calculation of $v_{r} \cdot k_{b}$, that is, less than or equal to the value of $c_{r}$. The value of $c_{r}$ also reflects the value of the error in the approximations. Errors greater than $30 \%$ are considered high in the literature in general. Thus, in this work, this pattern will be considered.

\subsection{The product transport}

The number of products transported by a conveyor in a given period, $p_{t}$, can be described according to the parameters as shown in Equation (3) (HILTERMANN et al., 2011).

$$
p_{t}=k \cdot\left(v_{0}-v_{0} \cdot v_{r}\right) \cdot\left(c_{0}+c_{0} \cdot c_{r}\right)
$$

In Equation (3) the number of parts transported by the belt is the product between the belt speed, the carrying capacity, and $k$, which is a scale conversion constant (HILTERMANN et al., 2011). $k$ is used to convert the time unit of the speed between days, hours, minutes and seconds, if necessary. $v_{r}$ and ${ }_{r}$ represent the percentage of speed reduction and the percentage of change in effective transport capacity. However, $v_{r}$ and ${ }_{r}$ are related by Equation (2) which forms a system of equations with Equation (3).

\section{METHODOLOGY}

Something around 20 videos related to conveyor belts, which was identified operating on the factory floor, was analyzed. The transport capacity was measured in the videos, and through this measurement, it was possible to conclude that belt conveyors were operating, on 
DOI: 10.14807/ijmp.v11i5.1284

average, with something around $44 \%$ of their transport capacity. For this procedure, the passage of each product on the belt conveyor is marked, the video is paused, areas occupied byproducts, and free on the belt conveyor are estimated, and then the ratio between these areas is calculated. Afterward, the video is advanced until the last marked product disappears from the screen, the video is paused again, and the whole procedure is repeated. An average was applied to the set of values, and that resulted in a value of $44 \%$ for the transport capacity.

An example of this type of mechanism can be seen in the video of the Piraquê's factory in Rio de Janeiro (DEMATIC LATIN AMERICA. Youtube: Dematic Reference Piraque, Rio de Janeiro - Portuguese, c2016. Available at: <https://www. youtube.com/watch?v = lFEAZmOul0>. Accessed on: Sept. 6, 2019.) showing a conveyor belt operating on the factory floor of a national industry. This initial study serves as a strong indication that efficient configurations related to operations with conveyor belts (speed adjustments) are not usually adopted in many national industries. The system of Equations (2) and (3) models the relationship between the reduction in speed and the effect that this reduction has on transport capacity and also the number of products transported in a period. Figure (1) shows the complete model used.

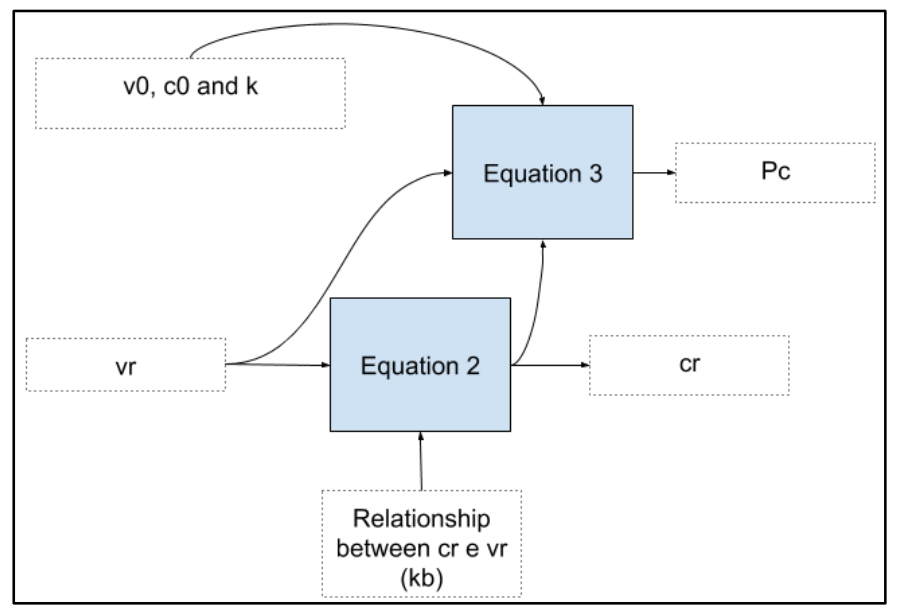

Figure 1: The model used for the calculation of the speed reduction impact in the number of products transported.

\subsection{Using the equations system}

To demonstrate the use of Equations (2) and (3) a case study of one of the analyzed videos will be presented. As defined in Equation (2), $k_{b}$ is the ratio between $c_{r}$ and $v_{r}$. It is assumed here that different belt conveyors have different parameters. This is due to the different construction characteristics of each of these devices. Thus, different belt conveyors 
respond differently to the same reduction in speed. In the analyzed video, parameter $k_{b}$ was measured - the estimate of this parameter depends on measurements made on a running belt.

To do this, you must maintain the number of parts that arrive at the belt per unit of constant time, vary the belt speed gradually and for each of these variations measure the number of parts transported by that belt at that same time.

Using Equation (3) it is possible to calculate the value of $c_{r}$ for each applied $v_{r}$. The linear adjustment of points $c_{r}$ and $v_{r}$ results in a line whose slope value is the value of parameter $k_{b}$. The measurement resulted in a $k_{b}$ equal to 0.9 . In the case study, we will consider four more tracks whose $k_{b}$ values are values around the calculated for the video. The $k_{b}$ parameters are equal to $0.7,0.8,0.9,1.0$ and 1.1 for the set of 5 tracks. When measuring the transport speed of the products by the conveyor (displacement by time) the video concluded that this speed is 2.25 products per second. For the case study, it will be assumed that all five belt conveyors have a $v_{0}$ speed of 2.25 products per second (same as the treadmill analyzed in the video).

An initial transport capacity $\left({ }^{c_{0}}\right.$ ) of $44 \%$ will also be adopted, a value achieved by analysis already presented. Thus, when Equation (3) is applied, it can be concluded that all five conveyors carry a quantity of 85536 products per day $\left(p_{c 0}\right)$ in the initial configuration. Simulating the model, Equation (3), it was possible to obtain the data shown in the Figure (2). The simulation $k$ was adjusted to convert the time unity from seconds to days, having a value defined in 86400 seconds per day. The speed $v_{0}$ of all five belt conveyor is reduced graduated from 0 to $25 \%$, it is calculated for each reduction $c_{r}$ (Equation (2)) and the amount of products(parts) transported per day (Equation (3)). The Figure (2) shows the calculated values by the Equations (2) and (3).

Simulating the model, Equation (3), it was possible to produce the data presented in Figure (2). In the simulation $k$ was adjusted to convert the speed time unit from seconds to days, having its value set at 86400 seconds per day. The $v_{0}$ speed of all five belts is reduced gradually from 0 to $25 \%$, it is calculated for each reduction $c_{r}$ (using Equation (2)) and the 
number of products (pieces) transported per day (using Equation (3)). Figure (2) shows the values calculated by Equations (2) and (3).

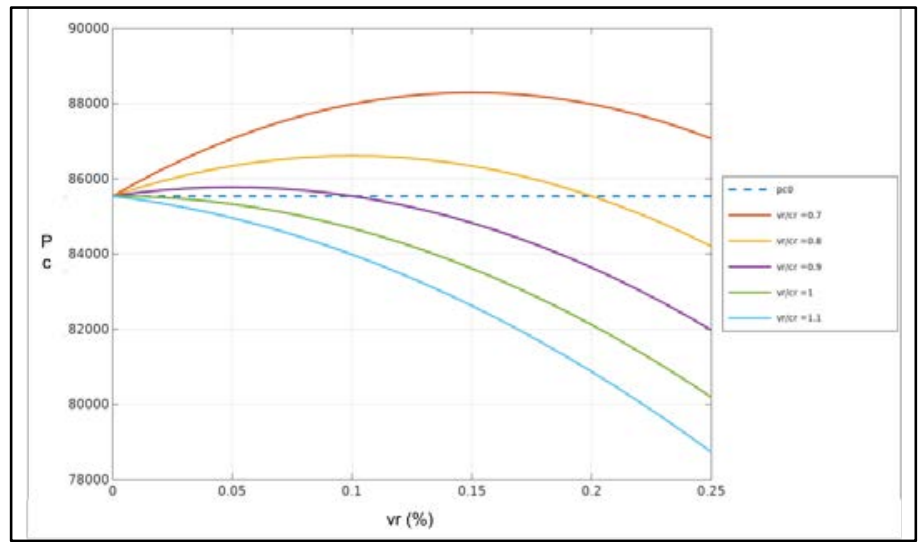

Figure 2: Five different belt conveyors are imagined with each one using different $k_{b}$ parameters. Equations (2) and (3) are used to simulate the behavior of transporting parts per day due to the reduction in speed for each of the belt conveyors. It was considered that all the belt conveyors initially had the same parameters of speed and effective transport capacity.

As expected, the behavior of the belt conveyor concerning the total transport of products is greatly altered when speed reductions occur. Looking at Figure (2) it is possible to observe that for the curve where $k_{b}$ is 0.9 , a $10 \%$ reduction in speed does not affect the total quantity of parts transported per day. As in this case, although there was a reduction in speed, there was also an increase in the transport capacity and thus the total quantity of parts transported per day was maintained. This increase in the effective transport capacity offset the decrease in speed. It is possible to observe that when $k_{b}$ is 1.0 the total quantity of products transported per day does not increase or is maintained with the reduction of speed.

\subsection{Establishing boundaries for the problem}

As has been seen, in some of the curves shown the reduction in speed also reduces the transport capacity. Thus, it is necessary to answer questions such as: - what is the maximum $k_{b}$ value that allows speed reductions without reducing transport capacity? For the answer to this question, we will have to solve the optimization problem presented in Equation (4).

$$
\text { maximizar } \rightarrow\left\{k_{b}=v_{r} / c_{r}\right\}
$$

Subject to the following restrictions: 


$$
\begin{aligned}
& p_{c 0}=k \cdot\left(v_{0}-v_{0} \cdot v_{r}\right) \cdot\left(c_{0}+c_{0} \cdot c_{r}\right) ; \\
& v_{r}>0 \\
& k_{b}>0 .
\end{aligned}
$$

As a solution to the problem, it was obtained that $k_{b}$ must be less than 1 so that all restrictions of the problem are met, which is the fundamental characteristic of the conveyor belt.

\section{RESULTS}

Using the model defined by the system of Equations (2) and (3) it is possible to draw a general solution model (a template) for the problem. This template shows several possible situations where different parameter settings can be compared. The results of the model simulations will be centered at the limit point of $\mathrm{K}$ since this limit is our reference and also for the reason that there may be situations where the total quantity of products transported per day by the belt conveyor falls so insignificantly with the reduction of the speed that it is possible to assume that point as being an acceptable point. In the simulations, a $p_{c 0}$ value of 85000 , a $v_{0}$ value of 2.25 products per second and a $c_{0}$ value of $44 \%$ will be used. Only speed reductions ( $v_{r)}$ that result in $c_{r}$ values below 0.3 (30\%) will be used.

A template containing several solutions that start from the initial belt setup point ( $p_{c 0}$, $v_{0}$, and $c_{0}$ ) is shown in Figure (3). These solutions include those solutions for belt conveyor that have the value of parameter $k_{b}$ ranging from 0.7 to 1.1 . The interpretation of the graph presented in Figure (3), although it seems complicated, is simple to understand. An example case will be used with a belt conveyor that has a $k_{b}$ parameter defined for a more accessible explanation. 
DOI: 10.14807/ijmp.v11i5.1284

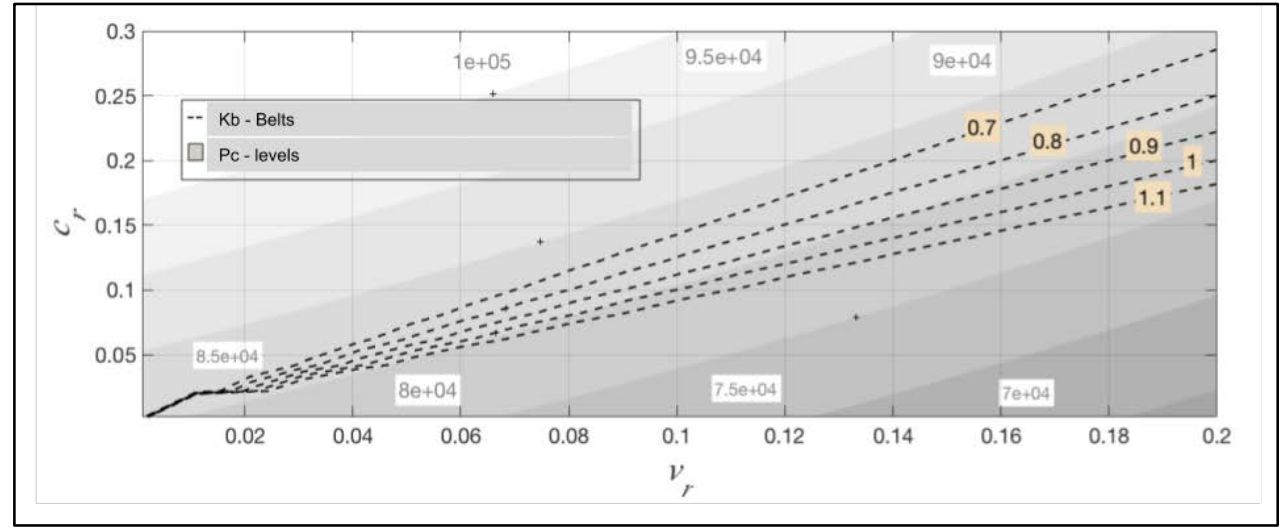

Figure 3: Five different belts conveyor are imagined with each one using different parameters $k_{b}$ and all starting from an initial configuration ( $p_{c 0}, v_{0}$ and $\left.c_{0}\right)$. As there is a reduction in the initial speed of the belts, each belt takes a different trajectory over the level curves that define the quantities of parts transported per day given a specific configuration.

You can imagine that the belt conveyor you want to adjust to is the one with a $k_{b}$ of 0.8. It is possible to see that it transports 85000 parts in its initial configuration with $p_{c 0}, v_{0}$, and $c_{0}$. With a reduction in speed of almost 20\% it still maintains that same amount of parts transported. In the graph, the dashed line 0.8 remains within the same level curve, 8.5E4. However, in this case, the estimate has a maximum error of 25\% (21250 pieces) for that point. With a $10 \%$ reduction in speed, the same number of products transported is maintained, however, now the maximum error of the estimate is around 12.5\% (10620 pieces).

The error related to the estimates is still high and a more accurate study on real situations of conveyors in operation could provide elements that would allow improving these estimates. Despite this, the feedback presented allows for a very clear view of the impact on the number of products transported when the belt speed is changed. Reductions in belt speed that do not cause changes in the number of products transported can be adopted as adjustment points that increase the energy efficiency of the set.

\section{CONSIDERATIONS}

In this work, the study of the relationship between the product transport capacity and speed on a conveyor belt was approached theoretically. A mathematical model (Equations (2) and (3)) for this relationship was developed and through this model, it was possible to demonstrate that in some situations it is possible to reduce the belt speed without changing one of the main functionalities within an industrial production line, the number of products transported by a belt conveyor within a certain period of time. This reduction in speed allows a reduction in the energy cost by operating the belt conveyor. Using the mathematical model, 
DOI: 10.14807/ijmp.v11i5.1284

it was possible to design a graphical solution (the template in Figure (3)) that allows easily adjusting the belt conveyor speed. This simplicity that the graphic tool offers for adjustments on the belt conveyor transport velocity is the main differential of this work when compared to the others already published.

This was a theoretical study, but it shows evidence that this behavior of belt conveyors can occur in real situations. That is why it is proposed, as future work, a practical study that proves this theoretical study. It is proposed also a theoretical study that investigates how the relationship between the percentage of speed reduction and the percentage of increased transport capacity is influenced by the quantity and distribution of secondary feeding lines (other conveyor belts that feed the main conveyor). This theoretical study is important, as it can show new ways to configure belt conveyors more efficiently.

\section{REFERENCES}

CHAPRA, S. C.; CANALE, R. P. (2016) Métodos Numéricos para Engenharia, 7 ed. Porto Alegre: AMGH.

DIAS, J. H.; LIMA, A. S.; TOSTES, M. E. (2008) Uso do método LQG-LTR para o controle de velocidade em transportadores de correia visando a eficiência energética. In: VIII CONFERÊNCIA INTERNACIONAL DE APLICAÇÕES INDUSTRIAIS. Proceedings... Poços de Caldas, 2008.

DIAS, S. V.; RAMALHO, G. L. B. (2009) Estimação da Velocidade de deslocamento de uma esteira transportadora utilizando redes neurais artificiais. In: IX ENPPG, IX ENICIT, III SIMPIT. Proceedings... Fortaleza, 2009.

HILTERMANN, J.; LODEWIJKS, G.; SCHOTT, D. L.; RIJSENBRIJ, J. C.; DEKKERS, J. A. J. M.; PANG, Y. (2011) A Methodology to Predict Power Savings of Troughed Belt Conveyors by Speed Control. Particulate Science and Technology, v. 29, n. 1, p. 14-27. DOI:10.1080/02726351.2010.491105.

NOGUEIRA, F. J. H. (2004) Correias Transportadoras - Guia Avançado. Procel Indústria, Rio de Janeiro.

ŠTATKIĆ, S.; VUKIĆ, D.; MILKIĆ, Z.; RISTIĆ, L. (2015) Energy efficiency of belt conveyor at constant speed operation. Mining \& Metallurgy Engineering Boor, n. 3, p. 33-42. DOI: 10.5937/MMEB1503033S

TSAI, M. C.; LEE, C. H. (1996) Tracking control of a conveyor belt: design and experiments. In: IEEE TRANS. ON ROBOTICS AND AUTOMATION, Proceedings... v. 12, n.1, p. 126131.

ZHANG, S.; XIA, X. (2010) Optimal Control of Operation Efficiency of Belt Conveyor Systems. Applied Energy. Applied Energy, v. 87, n. 6, p. 1929-1937. DOI: 10.1016/j.apenergy.2010.01.006 